\title{
Correlation between tests of small airway function
}

\author{
G. M. COCHRA N E, S.R.B ENA T A R, J. D A V I S, J. V. COLL I N S \\ and T. J. H. C L A R K \\ The Brompton Hospital, London SW3 and Institute of Diseases of the Chest, London SW3

\begin{abstract}
Cochrane, G. M., Benatar, S. R., Davis, J., Collins, J. V., and Clark, T. J. H. (1974.) Thorax, 29, 172-178. Correlation between tests of small airway function. To compare and correlate tests of small airway function we have measured residual volume, frequency dependence of compliance, 'closing volume', maximal expiratory flow rate at $50 \%$ and $25 \%$ of vital capacity, maximal expiratory flow rate at $50 \%$ of total lung capacity, and forced expired time in 10 healthy non-smoking male subjects and 10 non-smoking asthmatics who on the day of the study had no symptoms of airway obstruction. There was no evidence to suggest that any one particular test was more sensitive than others in detecting the presence of small airways obstruction. The closest correlation was between maximal expiratory flow rate at both $25 \%$ of vital capacity and $50 \%$ of total lung capacity and the forced expired time. It is argued that a prolonged forced expired time in the presence of normal dynamic lung volumes may be the most easily applicable screening test for early small airways obstruction.
\end{abstract}

The initial and probably major site of obstruction in diseases characterized by airways obstruction is now thought to be in airways less than 2 to $3 \mathrm{~mm}$ in diameter (Hogg, Macklem, and Thurlbeck, 1968). McFadden and Linden (1972) and Ingram and O'Cain (1971) have provided evidence that early small airways obstruction can be reversed by stopping smoking and by treatment with bronchodilators. As the small airways normally contribute less than $30 \%$ of the total airway resistance (Macklem and Mead, 1967) substantial abnormalities could occur in these airways before conventional tests of lung function become abnormal. It is therefore important to develop a simple, cheap, non-invasive, and accurate test to detect early small airways obstruction with a view to the prevention of chronic obstructive bronchitis.

Tests which have been used to detect small airways obstruction are measurements of dynamic compliance (Woolcock, Vincent, and Macklem, 1969), closing volume (McCarthy, Spencer, Greene, and Milic-Emili, 1972), and measurements of expiratory flow rate in the lower threequarters of the vital capacity (Mead, Turner, Macklem, and Little, 1967). In order to see whether there was any correlation or order of sensitivity between the tests presumed to be measuring small airways obstruction we have compared frequency dependence of compliance, residual volume, closing volume, maximal flow $\mathbb{D}$ rate at $50 \%$ of total lung capacity ( $\dot{\mathrm{V}}_{50}$ TLC), $\overrightarrow{\vec{P}}$ maximal flow rate at $50 \%$ of vital capacity $\left(\mathrm{MEF}_{50} \%\right)$, maximal flow rate at $25 \%$ of vital capacity $\left(\mathrm{MEF}_{75} \%\right.$ ), (Hyatt, 1963), and forced expired time in healthy subjects and symptom-free asthmatics.

\section{SUBJECTS, PATIENTS, AND METHODS}

SUBJECTS Ten healthy non-smoking male subjects, $\dot{0}$ aged 26-34 (mean 30) years, 172-187 (mean 178) $\mathrm{cm}$ in height, who had no previous history of lung disease and no recent lower respiratory tract infections were studied.

PATIENTS Four female and six male patients with asthma who were all skin test positive, non-smokers, and aged 20-58 (mean 30) years, 158-175 (mean ơ 170 ) $\mathrm{cm}$ in height were studied. The aims of the study were explained to each patient and consent was obtained. None of the patients on the study day had symptoms of asthma and all had been free from attacks of asthma requiring hospital admission in the previous six months. Apart from subject 16, none was receiving treatment.

METHODS The order of the tests as far as possible was kept constant. Forced expiratory manoeuvres were always done last to prevent any induction of airways obstruction in the asthmatic patients. The methods are described in the order the tests were carried out. Airway resistance breathing spontane- 
ously and panting at a rate of $60 /$ minute (to decrease upper airway resistance), and thoracic gas volume were measured in a constant volume body plethysmograph (Fenyves, Pulmostar SMB) (Dubois, Botelho, and Comroe, 1956b; Dubois et al., 1956a). Resistance was converted to its reciprocal, conductance, and expressed as the ratio of conductance to thoracic gas volume, termed specific conductance (Briscoe and Dubois, 1958).

Dynamic lung compliance was obtained as follows. An oesophageal balloon, wall thickness $0.005 \mathrm{~cm}$, $10 \mathrm{~cm}$ long and $3.2 \mathrm{~cm}$ in circumference, containing $0.5 \mathrm{ml}$ of air and attached to a polyethylene catheter, internal diameter $0.232 \mathrm{~cm}$, was positioned approximately $38-42 \mathrm{~cm}$ from the nose at the junction of the middle and lower thirds of the oesophagus to minimize cardiac artefact (Milic-Emili, Mead, Turner, and Glauser, 1964). The internal diameter of the polyethylene tubing was large to prevent any phase lag created by the resistance of the tubing. Transpulmonary pressure (pressure difference between mouth and oesophagus) was measured with a Mercury Electronic A300 capsule with a volume displacement coefficient of $0.005 \mathrm{ml} / \mathrm{cm} \mathrm{H}_{2} \mathrm{O}$ and a frequency response flat to over $3 \mathrm{~Hz}$ with a volume of $500 \mathrm{ml}$ but with a $5 \%$ reduction in response at $5 \mathrm{~Hz}$. Volume was recorded on an Ohio 800 spirometer and flow was obtained by electrical differentiation, the frequency response of the spirometer being linear to over $5 \mathrm{~Hz}$.

Pressure, volume, and flow were recorded on a Consolidated Electrodynamics recording oscillograph type 5-124. Phase lag between pressure and flow was excluded up to $3 \mathrm{~Hz}$. The large volume displacement coefficient of the catheter manometer system necessary for the measurement of dynamic compliance prevented measurement of the absolute static elastic recoil pressures but nevertheless permitted the measurement of static compliance from the slope of the curve close to functional residual capacity, expiratory pressure volume curves being obtained from quasistatic manoeuvres (flow rates less than $300 \mathrm{ml} / \mathrm{sec}$ ) preceded by a constant volume history. Dynamic compliance was measured at 20,30, 40, and 60 breaths per minute; a constant tidal volume and functional residual capacity were maintained by watching the volume changes recorded from the spirometer on a projection module screen. The respiratory rate was imposed by verbal instruction, care being taken to preserve as far as possible the inspiratory: expiratory time ratio. The mean of 8 to 10 individual measurements of dynamic compliance at each frequency was calculated. Dynamic compliance at 20 breaths per minute was taken as the basal value; it was found that the value at an imposed breathing frequency of 20 per minute was slightly lower than at a natural frequency of 20 .

'Closing volume' was measured with xenon-133 using the technique described by Dollfuss, Milic-Emili, and Bates (1967). Volume changes were determined with a Morgan M2 spirometer equipped with a rotational potentiometer (Bourne). The expired radioactivity was determined by a scintillation counter (E.R.D. Engineering) and the volume and counts per minute were recorded on an $\mathrm{X}-\mathrm{Y}$ recorder (Hewlett Packard 7005 B). The procedure was carried out three to five times and the results were expressed as the mean phase 4/vital capacity (VC) ratios at ATPS. Phase 4 is the volume of the vital capacity at which airways begin to close in the dependent zones of the lungs.

Thoracic gas volume (VTG) was measured three to five times by the methods of Dubois et al. (1956a) in a body plethysmograph. Inspiratory capacity and expiratory reserve volume were recorded on an Ohio spirometer after each measurement of functional residual capacity. Maximum expiratory curves were recorded three to five times, the forced vital capacity being instituted from the first deep breath taken from resting tidal breathing level after the measurement of thoracic gas volume. The characteristics of the plethysmograph when used in the pressure-corrected volume displacement mode (Mead, 1960) were such that the frequency amplitude response was flat to $5 \mathrm{H}_{\mathrm{z}}$ and there was no phase shift up to this frequency when tested with a volume of 0.5 litre. Expired volume was recorded on the $\mathrm{X}$ axis of a Bryans XYY plotter and on a Mingograph 34T. Expired flow rate was obtained by the differential of the volume signal (Ohio 800) and recorded on the $Y$ axis of the Bryans plotter (frequency amplitude response flat to $5 \mathrm{~Hz}$ over a 2 in excursion on the $Y$ axis), the $Y$ axis on a Tetronix 564 storage oscilloscope and on the Mingograph. Thoracic gas volume change was measured by integrating the signal produced by the pressure drop across the two $8 \mathrm{~cm}$ diameter mesh screens (low flow resistance and linear response up to 450 litres per minute) and was recorded on the $\mathrm{X}$ axis of the storage oscilloscope and on the Mingograph. $\mathrm{MEF}_{50 \%}$ and $\mathrm{MEF}_{75} \%$ were obtained from the curve recorded on the Bryans plotter and $\dot{V}_{50}$ TLC by relating the maximum expiratory flow/thoracic gas volume change curve recorded on the oscilloscope to the measured TLC. $\dot{V}_{\text {so }}$ TLC was expressed as flow in TLC per second to correct for difference in lung size (Zapletal et al., 1969).

Peak expiratory flow rate (PEFR), forced expired volume in one second $\left(\mathrm{FEV}_{1}\right)$, forced vital capacity (FVC), the FEV 1 and FVC ratio, and forced expired time (FET) were obtained from the mouth flow, the volume traces being recorded against time and expressed as litres BTPS, litres/second, and seconds.

All the pulmonary function studies were performed in the sitting position with as near as possible identical mouthpiece height for each subject and each manoeuvre.

\section{RESULTS}

NORMALS The results expressed as per cent predicted for the normal subjects are shown in Table I. 
T A B L E I

RESULTS FOR NORMAL SUBJECTS EXPRESSED AS PERCENT PREDICTED

\begin{tabular}{|c|c|c|c|c|c|c|c|c|c|c|}
\hline Subject & $\mathbf{R V}$ & $\mathrm{FEV}_{1} / \mathrm{FVC}$ & FVC & $\mathrm{FEV}_{1}$ & MEF $_{50 \%}$ & $\mathrm{MEF}_{75 \%}$ & $\dot{\mathrm{V}}_{50}$ TLC & FET (sec) & Phase 4/VC & FDC $60 / 20$ \\
\hline $\begin{array}{c}1 \\
2 \\
3 \\
4 \\
5 \\
6 \\
7 \\
8 \\
9 \\
10 \\
\text { Mean }\end{array}$ & $\begin{array}{r}80 \\
145 \\
100 \\
116 \\
125 \\
97 \\
97 \\
75 \\
105 \\
105 \\
104\end{array}$ & $\begin{array}{r}97 \\
94 \\
97 \\
93 \\
104 \\
89 \\
102 \\
103 \\
106 \\
87 \\
97\end{array}$ & $\begin{array}{r}123 \\
117 \\
117 \\
112 \\
116 \\
100 \\
85 \\
114 \\
120 \\
117 \\
112\end{array}$ & $\begin{array}{r}119 \\
110 \\
118 \\
105 \\
122 \\
89 \\
88 \\
118 \\
125 \\
101 \\
104\end{array}$ & $\begin{array}{r}88 \\
79 \\
83 \\
103 \\
113 \\
67 \\
71 \\
90 \\
111 \\
60 \\
86\end{array}$ & $\begin{array}{r}76 \\
78 \\
76 \\
103 \\
87 \\
60 \\
56 \\
92 \\
85 \\
48 \\
76\end{array}$ & $\begin{array}{r}128 \\
84 \\
90 \\
90 \\
134 \\
90 \\
147 \\
112 \\
155 \\
76 \\
111\end{array}$ & $\begin{array}{l}3 \cdot 9 \\
2.9 \\
3 \cdot 7 \\
3 \cdot 5 \\
2 \cdot 5 \\
5 \cdot 0 \\
3 \cdot 5 \\
3 \cdot 0 \\
3 \cdot 9 \\
4 \cdot 8 \\
3 \cdot 6\end{array}$ & $\begin{array}{r}121 \\
132 \\
133 \\
140 \\
81 \\
101 \\
101 \\
103 \\
103 \\
84 \\
110\end{array}$ & $\begin{array}{l}84 \\
91 \\
84 \\
67 \\
77 \\
77 \\
68 \\
81 \\
77 \\
88 \\
79\end{array}$ \\
\hline
\end{tabular}

The values shown in bold type are considered to be outside the normal range:

RV $>25 \%$ predicted (Goldman and Becklake, 1959)

$\mathrm{FEV}_{1} / \mathrm{FVC}<85 \%$ predicted in males (Cotes et al., 1966)

$\mathrm{FEV}_{1} / \mathrm{FVC}<89 \%$ predicted in females (Ferris et al., 1965)

MEF $_{50} \%$, MEF $_{75 \%}<75 \%$ predicted (Cherniak and Raber, 1972)

$\widehat{V}_{50}$ TLC $<80 \%$ predicted (Mead et al., 1967)

FET $>4.5$ seconds

Phase 4/VC $>95 \%$ tolerance limits for the linear regression of $4 / \mathrm{VC}$ with age (Collins et al., 1973)

FDC 60/20 A fall in C dyn at 60 breaths/minute $>25 \%$ of C dyn at an imposed frequency of 20 breaths/minute.

The values for static compliance and specific conductance were within the normal range (Cotes, 1968) and the majority of results for the other tests were also normal. However, subject 2 had an abnormally large residual volume, subjects 4 and 7 an abnormal fall in dynamic compliance with increasing breathing frequencies, subject 10 a reduced $\dot{V}_{50}$ TLC, and subiects 6 and 10 a prolonged forced expired time. Subjects 6, 7, and 10 had a low $\mathrm{MEF}_{75} \%$.

PATIENTS The asthmatic patients were divided into two groups: The first had dynamic lung volumes within the normal range (Table II) while the second group, although symptom-free when studied and having specific conductances within the normal range, had reduced dynamic lung volumes $\left(\mathrm{FEV}_{1}<80 \%\right)$ (Table III). The static compliance was within the normal range in both groups apart from subject 16 , in whom it was increased.

Of the patients with asthma and normal $\mathrm{FEV}_{1}$, subject 11 had a raised residual volume (RV), frequency dependence of compliance, and phase 4/VC ratio. Subjects 12 and 14 were abnormally frequency dependent (Table II). Subject 16 had

T A B L E I I

RESULTS FOR SYMPTOM-FREE ASTHMATIC PATIENTS WITH NORMAL FEV ${ }_{1}$ EXPRESSED AS PERCENT PREDICTED

\begin{tabular}{|c|c|c|c|c|c|c|c|c|c|c|}
\hline Subject & RV & $\mathrm{FEV}_{1} / \mathrm{FVC}$ & FVC & $\mathrm{FEV}_{1}$ & MEF $_{50 \%}$ & $\operatorname{MEF}_{7 s \%}$ & $\dot{\mathrm{V}}_{s 0} \mathrm{TLC}$ & FET $(\mathrm{sec})$ & Phase 4/VC & FDC $60 / 20$ \\
\hline $\begin{array}{c}11 \\
12 \\
14 \\
16 \\
17 \\
\text { Mean }\end{array}$ & $\begin{array}{r}171 \\
81 \\
99 \\
165 \\
121 \\
127\end{array}$ & $\begin{array}{l}94 \\
95 \\
98 \\
99 \\
87 \\
95\end{array}$ & $\begin{array}{r}117 \\
97 \\
105 \\
111 \\
123 \\
110\end{array}$ & $\begin{array}{c}111 \\
92 \\
103 \\
110 \\
106 \\
104\end{array}$ & $\begin{array}{l}92 \\
99 \\
80 \\
56 \\
69 \\
79\end{array}$ & $\begin{array}{l}59 \\
66 \\
66 \\
46 \\
53 \\
58\end{array}$ & $\begin{array}{r}92 \\
141 \\
137 \\
22 \\
69 \\
92\end{array}$ & $\begin{array}{l}4.0 \\
5.1 \\
3.8 \\
8.4 \\
5.3 \\
5.6\end{array}$ & $\begin{array}{c}492 \\
134 \\
112 \\
96 \\
161 \rightarrow \\
199\end{array}$ & $\begin{array}{l}73 \\
56 \\
62 \\
86 \\
81 \\
68\end{array}$ \\
\hline
\end{tabular}

The values shown in bold type are considered to be outside the normal range (see legend to Table I). The value $\infty$ denotes a closing volume trace in which there was no phase 4 , only an upward sloping phase 3 .

T A B L E I I I

RESULTS FOR SYMPTOM-FREE ASTHMATIC PATIENTS WITH REDUCED FEV ${ }_{1}$ EXPRESSED AS PERCENT PREDICTED

\begin{tabular}{|c|c|c|c|c|c|c|c|c|c|c|}
\hline Subject & RV & $\mathrm{FEV}_{1} / \mathrm{FVC}$ & FVC & FEV $_{1}$ & $\mathrm{MEF}_{\mathrm{s} 0 \%}$ & $\mathrm{MEF}_{75 \%} \%$ & $\dot{\mathrm{V}}_{50}$ TLC & FET $(\mathrm{sec})$ & Phase 4/VC & FDC $60 / 20$ \\
\hline $\begin{array}{c}13 \\
15 \\
18 \\
19 \\
20 \\
\text { Mean }\end{array}$ & $\begin{array}{r}98 \\
140 \\
157 \\
70 \\
138 \\
120\end{array}$ & $\begin{array}{l}80 \\
71 \\
57 \\
77 \\
63 \\
70\end{array}$ & $\begin{array}{r}97 \\
110 \\
86 \\
96 \\
87 \\
95\end{array}$ & $\begin{array}{l}77 \\
78 \\
48 \\
74 \\
61 \\
68\end{array}$ & $\begin{array}{l}46 \\
38 \\
15 \\
44 \\
49 \\
38\end{array}$ & $\begin{array}{l}36 \\
29 \\
16 \\
26 \\
25 \\
26\end{array}$ & $\begin{array}{r}58 \\
38 \\
4 \\
86 \\
39 \\
46\end{array}$ & $\begin{array}{l}5.8 \\
5.1 \\
5.4 \\
5.8 \\
6.0 \\
5.6\end{array}$ & $\begin{array}{c}\infty \\
325 \\
\infty \\
365 \\
\infty \\
345\end{array}$ & $\begin{array}{l}73 \\
78 \\
90 \\
93 \\
83\end{array}$ \\
\hline
\end{tabular}

The values shown in bold type are considered to be outside the normal range (see legend to Table I). $\infty$ See footnote to Table II. 
a raised residual volume while subject 17 had an abnormally raised phase $4 / \mathrm{VC}$ ratio, both these subjects having decreased $V_{50}$ TLC and increased forced expired time. All these patients had a reduced $\mathrm{MEF}_{75} \%$. An interesting observation in subject 17 was the way the phase 4/VC increased with successive 'closing volume' manoeuvres until on the fifth measurement there was no phase 4 but only an upward sloping phase 3 , suggesting that airways obstruction was being induced despite the low flow rates of this manoeuvre $(300 \mathrm{ml} / \mathrm{sec})$.

In those patients with asthma and a reduced $\mathrm{FEV}_{1}$ all the tests incorporating the forced expiratory manoeuvre were abnormal (Table III). However, only patient $\mathbf{1 3}$ had abnormal frequency dependence of compliance, three other subjects showing no frequency dependence of compliance. Subject 18 was unable to tolerate the balloon.

\section{DISCUSSION}

As approximately $50 \%$ of the British population. smokes but only 7 to $10 \%$ of the population develops severe chronic airways obstruction a test which will predict at a presymptomatic stage those smokers who are liable to develop disabling airway obstruction would be helpful.

The earliest abnormality in routine lung function assessment in patients with simple chronic bronchitis is considered to be an increase in residual volume (Bates et al., 1966). However, residual volume changes probably occur late in the natural history of chronic bronchitis, and more sensitive tests to detect early small airways obstruction have been sought. Woolcock et al. (1969)suggested that the diagnosis of small airways obstruction could be made by showing a marked fall in dynamic compliance with increasing breathing frequencies. Abnormalities of ventilation distribution and gas exchange were shown by Levine, Housley, MacLeod, and Macklem (1970) to occur in patients with simple bronchitis or asymptomatic asthma before abnormalities in routine lung function occurred; these results probably reflect small airways obstruction and consequent ventilation and perfusion abnormality. Measurement of premature airway closure leading to an increase in closing volume has also been suggested by McCarthy et al. (1972) as a simple test for early detection of small airway obstruction.

Mead et al. (1967) have also argued that in the lower three-quarters of the vital capacity, maximum expiratory flow rates reflect the dimensions of the airways between alveoli and points in the airways where lateral airway pressure during forced expiration equals pleural pressure. As residual volume is approached these "equal pressure points' move into the smaller bronchi. Hence reduction in maximal expiratory flow rates in the lower part of the vital capacity should reflect reduction in airflow through the small peripheral airways.

In only one test (frequency dependence of compliance) have the postulated pathological changes in the small airways been supported by histological studies (Woolcock et al., 1969).

Have the tests been correlated? McFadden and Linden (1972) found a close correlation between maximal mid flow rate, frequency dependence of compliance and gas exchange abnormalities. Hill, Landau and Phelan (1972) found little correlation between frequency dependence of compliance and a reduction in $\dot{V}_{50}$ TLC in their study of adolescent symptom-free asthmatics, whereas Gelb and Zamel (1973) reported close correlation between abnormalities of closing volume and a reduction in flow at $50 \%$ of TLC. It should be noted that the latter study related exhaled flow rates and volume measured at the mouth rather than exhaled flow rates against thoracic gas volume change.

Although tests of distribution of inspired air and gas exchange are accurate tests in the laboratory they are unsuitable for screening surveys, and abnormalities are not caused exclusively by small airways obstruction. Frequency dependence of compliance should be a sensitive test but for technical reasons it is unlikely to be useful in screening populations.

Fry and Hyatt (1960) showed from isovolume pressure flow curves that during forced expiration the rate of airflow cannot increase beyond certain maximum values; at large lung volumes these maximum values depend mainly on the amount of expiratory effort; at smaller lung volumes maximum flow rate becomes largely independent of the effort applied once this exceeds a certain minimum. Maximum respiratory flow volume curves are thus potentially the most useful for assessing airflow obstruction. In young healthy subjects, however, the terminal portion of the MEFV curve may be effort dependent (Leith and Mead, 1967), and the MEFV curve less useful in assessing airflow obstruction unless as a result of any disease the determinants of $\mathrm{RV}$ in these subjects resemble the mechanisms postulated for older subjects.

PRESENT STUDY There was no consistent pattern of abnormality and the best agreement appeared 
to be between $\mathrm{MEF}_{75 \%}, \dot{\mathrm{V}}_{50}$ TLC, and forced expired time. The test which deviated most from this predicted normal range chosen appeared to be $\mathrm{MEF}_{75 \%}$; this applied to all the patients with asthma and to three normal subjects having a reduced flow. However, it is difficult to compare the results of $\mathrm{MEF}_{75} \%$ with any of the other tests as the predicted values (Cherniack and Raber, 1972) were obtained from a non-smoking population living in non-polluted areas, and their normal values for flow rates at various percentages of vital capacity appear too high and this may be related to their apparently low FVC. This may account for the abnormally low flow rates found in our normal subjects. The relationship of the mean percent predicted for $\mathrm{FEV}_{1} / \mathrm{FVC}$, FVC, $\mathrm{FEV}_{1}, \quad \mathrm{MEF}_{50} \%, \quad \mathrm{MEF}_{75} \%, \mathrm{FET}$, and phase $4 / \mathrm{VC}$ for the normals (excluding subjects 6,7 , and 10) and for the two groups of asthmatic patients are shown in Fig. 1; there is substantial correspondence between all the tests.

Subject 16 has been excluded from the mean values for the asthmatic patients with normal $\mathrm{FEV}_{1}$ as his static compliance was higher than the normal range and this decreased lung recoil pressure would alter the maximum expiratory flow curve.

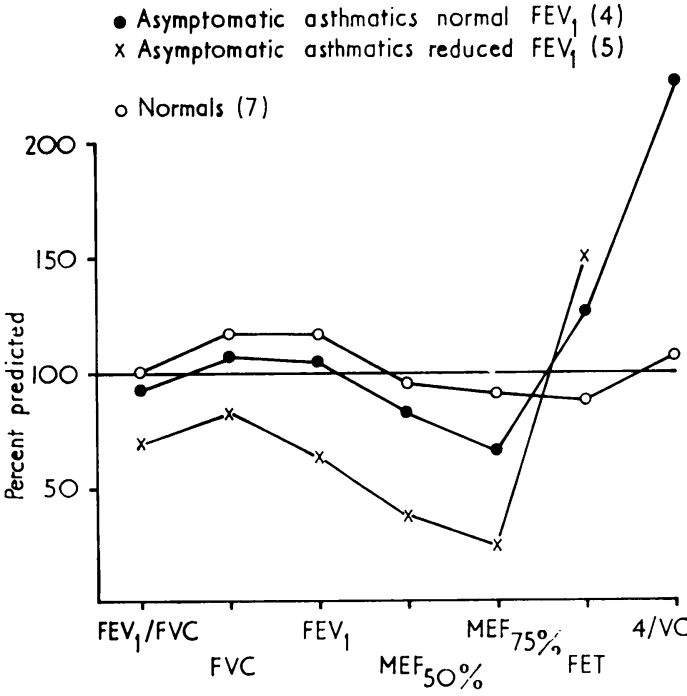

FIG. 1. Mean values, expressed as percent predicted, for the normal subjects (excluding 6, 7, and 10), asymptomatic asthmatics with normal FEV (excluding subject 16), and the asymptomatic asthmatics with reduced $F E V_{1}$. The forced expired time is expressed as a percentage of the mean time of $3.7 \mathrm{sec}$ taken from McFadden and Linden (1972).
$\mathrm{MEF}_{75} \%, \mathrm{FET}$, and phase $4 / \mathrm{VC}$ showed a $\stackrel{\overrightarrow{\mathrm{S}}}{\mathrm{F}}$ good correlation but unfortunately at present there $\bar{c}$ are problems with all these measurements. Al- $\overline{\underline{D}}$ though closing volume measurements are simple $\frac{\bar{D}}{\vec{D}}$ and inexpensive, the wide tolerance limits of the $\mathbb{\mathbb { Q }}$ normal values may diminish the value of this technique as a screening test. Difficulties with $\mathrm{MEF}_{75 \%}$ include the technical difficulties of ? measuring low flow rates and small volumes; in $\overrightarrow{\vec{\omega}}$ addition, these measurements are susceptible to small errors in delivering vital capacity so that if $\vec{x}$ a percentage of vital capacity is taken at which to i measure the flow rate (i.e., $25 \%$ ) a large variation is in flow rate can be obtained. Unfortunately, the intra-individual and inter-individual variations for $\mathrm{N}$ $\mathrm{MEF}_{75 \%}$ are not reported by Cherniack and 응 Raber (1972).

Forced expired time Because of the difficulties with $\mathrm{MEF}_{75} \%$ forced expired time would appear $\frac{\rho}{\square}$ useful as a screening test. It seems surprising that $\vec{\theta}$ forced expired time might reflect small airways obstruction, but in the presence of a normal $\mathrm{FEV}_{1}, 75$ to $80 \%$ of the vital capacity is expelled in the first second, the remaining 20 to $25 \%$ taking a further 2 seconds. If there is small airways obstruction the flow rates during the final portion of the forced vital capacity manoeuvre are decreased and thus the time taken to exhale the terminal volume is increased.

The relationship between FET and $\mathrm{MEF}_{75 \%}$ in the lower range of vital capacity with a normal $\mathrm{FEV}_{1}$ is shown in Fig. 2. This is a flow volume curve plotted with time from a patient with mitral stenosis and left heart failure. The FEV

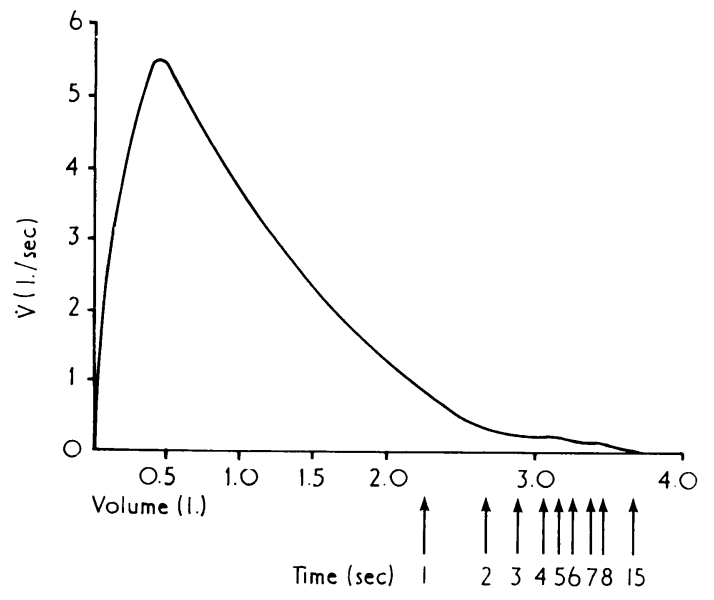

FIG. 2. Flow volume curve plotted with time in a patient with mitral stenosis and left heart failure. 
was within the normal range but his forced expired time was 15 seconds with a reduced $M E_{75} \%$. Evidence from McFadden and Linden (1972) supports the idea of FET as a measure of small airways obstruction; they showed that smokers with symptoms but no reduction in $\mathrm{FEV}_{1}$ had a prolonged FET of $7 \cdot 8 \pm 1 \cdot 8$ seconds.

An immediate problem associated with the use of FET as a screening test is lack of normal data. Roy, Chapin, and Favre (1955) studied dynamic lung volumes with time in normal subjects and for men aged 20 to 39 showed a mean FET of 2.18 seconds. This value is considerably lower than that quoted by McFadden and Linden (1972) and is also lower than the mean FET for the normal subjects in this study ( 3.6 seconds). The use of the lower values from Roy et al. (1955) does not alter our conclusions.

In conclusion, the currently accepted methods of detecting early small airways obstruction are unlikely to be applied widely because of the technical limitations of the tests. The value of the forced expiratory manoeuvre is increasingly recognized, and measurement of the total time taken to expel FVC may be as useful as the more complicated methods; but before FET can be used to screen populations for early small airways obstruction the normal range must be determined and information is required about the reproducibility of the method.

G.M.C. was supported by a grant from the Board of Governors of the National Heart and Chest Hospitals. S.R.B. was supported by an ICI Clinical Research Grant.

\section{REFERENCES}

Bates, D. V., Gordon, C. A., Paul, G. I., Snidal, D. P., and Woolf, C. R. (1966). Report on the 3rd and 4th stages of the co-ordinated study of chronic bronchitis in the Department of Veterans Affairs. Canadian Medical Services Journal, 22, 5.

Briscoe, W. A. and Dubois, A. B. (1958). The relationship between airway resistance, airway conductance and lung volume in subjects of different age and body size. Journal of Clinical Investigation, 37, 1279.

Cherniack, R. M. and Raber, M. B. (1972). Normal standards for ventilatory function using an automated wedge spirometer. American Review of Respiratory Diseases, 106, 38.

Collins, J. V., Clark, T. J. H., McHardy-Young, S., Cochrane, G. M., and Crawley, J. (1973). Closing volume in healthy non-smokers. British Journal of Diseases of the Chest, 67, 19.

Cotes, J. E. (1968). Lung Function, 2nd edition. Blackwell Scientific Publications, Oxford.
, Rossiter, C. E., Higgins, I. T. T., and Gibson, J. C. (1966). Average normal values for the forced expiratory volume in white Caucasian males. British Medical Journal, 1, 1016.

Dollfuss, R. E., Milic-Emili, J., and Bates, D. V. (1967). Regional ventilation of the lung studied with boluses of ${ }^{133}$ xenon. Respiratory Physiology, 2, 234.

Dubois, A. B., Botelho, S. Y., Bedell, G. N., Marshall. R., and Comroe, J. H. Jnr. (1956a). A rapid plethysmographic method for measuring thoracic gas volume; a comparison with a nitrogen washout method for measuring functional residual capacity in normal subjects. Journal of Clinical Investigation, 35, 322.

- and Comroe, J. H. Jnr. (1956b). A new method for measuring airway resistance in man using a body plethysmograph; values in normal subjects and in patients with respiratory disease. Journal of Clinical Investigation, 35, 327.

Ferris, B. J. Jnr., Anderson, D. O., and Zickmantel, R. (1965). Prediction values for screening tests of pulmonary function. American Review of Respiratory Diseases, 91, 252.

Fry, D. L. and Hyatt, R. E. (1960). Pulmonary mechanics. A unified analysis of the relationship between pressure, volume and gas flow in the lungs of normal and diseased human subjects. American Journal of Medicine, 29, 672.

Gelb, A. F. and Zamel, N. (1973). Simplified diagnosis of small-airway obstruction. New England Journal of Medicine, 288, 395.

Goldman, H. I. and Becklake, M. R. (1959). Respiratory function tests: Normal values at median altitudes and the prediction of normal results. American Review of Tuberculosis and Pulmonary Diseases, 79, 457.

Hill, D. J., Landau, L. I. and Phelan, P. D. (1972). Small airway disease in asymptomatic asthmatic adolescents. American Review of Respiratory Diseases, 106, 873.

Hogg, J. C., Macklem, P. T., and Thurlbeck, W. M. (1968). Site and nature of airway obstruction in chronic obstructive lung disease. New England Journal of Medicine, 278, 1355.

Hyatt, R. E. (1963). Dynamic lung volumes. In Handbook of Physiology, Section 3, Respiration. Vol. II, p. 1381. American Physiological Society, Washington, DC

Ingram, R. H. Jnr. and O'Cain, C. F. (1971). Frequency dependence of compliance in apparently healthy smokers versus non-smokers. Bulletin Physio-pathologie Respiratoire (Nancy), 7, 195.

Leith, D. E. and Mead, J. (1967). Mechanisms determining residual volume of the lungs in normal subjects. Journal of A pplied Physiology, 23, 221.

Levine, G., Housley, E., MacLeod, P., and Macklem, P. T. (1970). Gas exchange abnormalities in mild bronchitis and asymptomatic asthma. New England Journal of Medicine, 282, 1277. 
Macklem, P. T. and Mead, J. (1967). Resistance of central and peripheral airways measured by a retrograde catheter. Journal of Applied Physiology, 22, 395.

McCarthy, D. S., Spencer, R., Greene, R., and MilicEmili, J. (1972). Measurement of 'closing volume' as a simple and sensitive test for early detection of small airway disease. American Journal of Medicine, 52, 747.

McFadden, E. R. Jnr. and Linden, D. A. (1972). A reduction in maximum mid-expiratory flow rate; a spirographic manifestation of small airway disease. American Journal of Medicine, 52, 725.

Mead, J. (1960). Volume displacement body plethysmograph for respiratory measurements in human subjects. Journal of A pplied Physiology, 15, 736.

, Turner, J. M., Macklem, P. T., and Little, J. B. (1967). Significance of the relationship between lung recoil and maximum expiratory flow. Journal of Applied Physiology, 22, 95.

Milic-Emili, J., Mead, J., Turner, J. M., and Glauser, E. M. (1964). Improved technique for estimating pleural pressure from esophageal balloons. Journal of A pplied Physiology, 19, 207.
Otis, A. B., McKerrow, C. B., Bartlett, R. A., Mead, J., McIlroy, M. B., Selverstone, N. J., and ס Radford, E. P. Jnr. (1956). Mechanical factors in distribution of pulmonary ventilation. Journal of Applied Physiology, 8, 427.

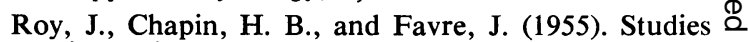
in pulmonary ventilatory function. 1. Vital @) capacity, first one-second capacity, and forced respiratory curves in patients with asthma: com- 0 parative evaluation of methods. Journal of Allergy, 26, 490.

Woolcock, A. J., Vincent, N. J., and Macklem, P. T. (1969). Frequency dependence of compliance as a test for obstruction in the small airways. Journal of Clinical Investigation, 48, 1097.

Zapletal, A., Motoyama, E. K., van de Woestijne, ! K. P., Hunt, V. R., and Bouhuys, A. (1969). Maximum expiratory flow-volume curves and airway conductance in children and adolescents. Journal of Applied Physiology, 26, 308.

Requests for reprints to: Dr. G. M. Cochrane, 令 Respiratory Function Unit, Guy's Hospital, St. Thomas Street, London SE1 9RT. 